\title{
Trabalho e Transtornos Mentais Graves: Breve Histórico e Questões Contemporâneas
}

Work and mental IIlness:

Brief historical review and contemporary questions

Paulo César

Zambroni -deSouza

Universidade do Federal de Itajubá
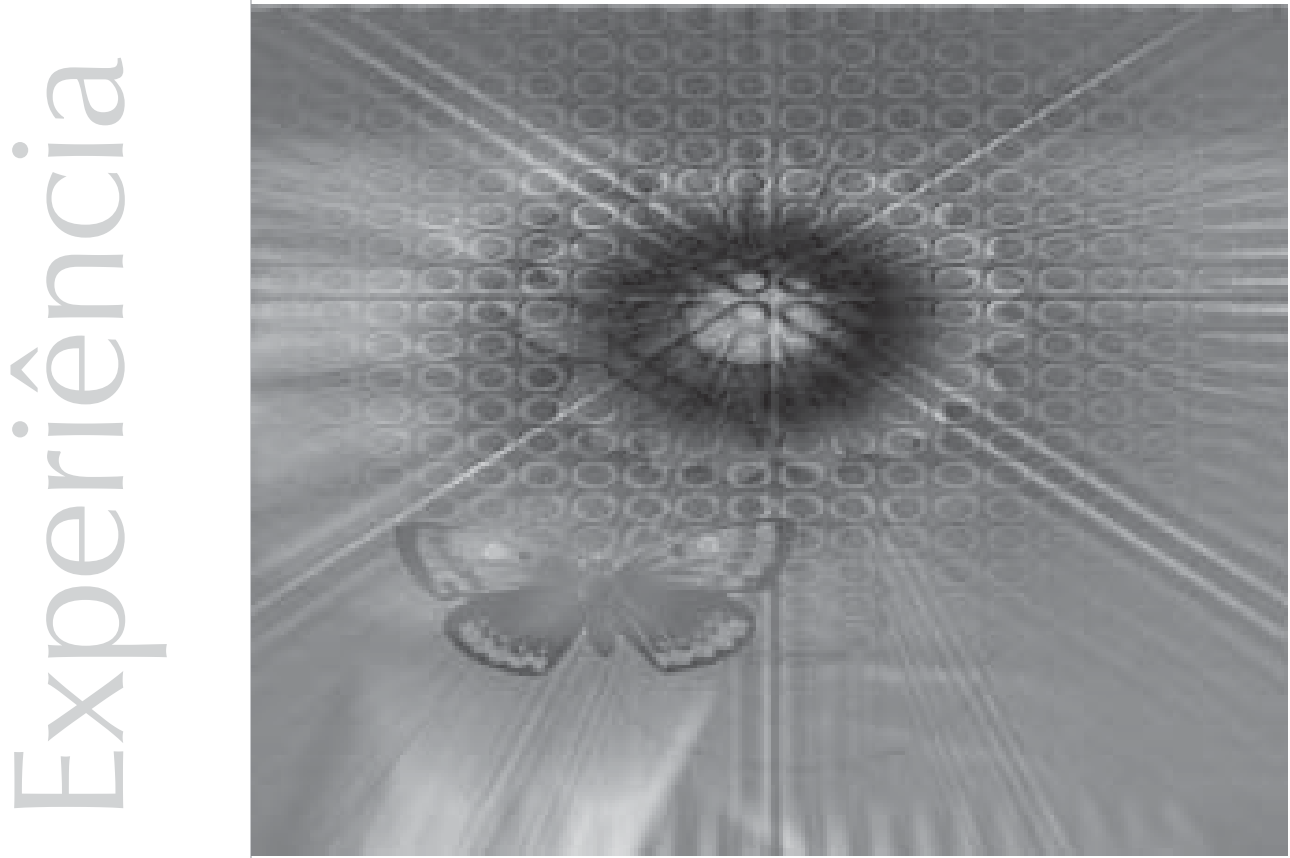
Resumo:Este artigo mostra que o nascimento da psiquiatria se insere em um processo de disciplinamento da sociedade; por isso, o asilo, ou hospício, originalmente seu lugar de exercício por excelência, guarda muitas semelhanças com outras estruturas disciplinares, como a prisão. Posteriormente, mostra como, a partir da Segunda Guerra Mundial, houve uma transformação nas sociedades ocidentais, onde aquelas estruturas disciplinares entraram em declínio e formas de controle social mais sutis ganharam força. Trabalha-se, ao lado disso, um processo de questionamento da própria psiquiatria e das estruturas manicomiais, o que genericamente se denominou reforma psiquiátrica, na qual o trabalho das pessoas com transtorno mental foi tomado como elemento essencial. Por fim, realiza-se uma breve contextualização das transformações recentes nos processos de produção para perguntar de que maneira as pessoas com transtornos mentais graves podem colocar-se no mundo do trabalho.

Palavras-chave: trabalho, disciplina, controle, reforma psiquiátrica.

Abstract AThis article demonstrates that psychiatry beginning is inserted in a process of society disciplinary value. That's why the asylum, or madhouse, originally its place of exercise by excellence, keeps many similarities with other disciplinary structures, like prisons. Afterwards, it shows that from World War II there was a changing in the eastern societies, where those disciplinary structures began to declive and more subtle social control ways gained strength. It shows, beside this, that there was a process of questioning psychiatry and madhouse structures, what generically was called psychiatrical reform, in which the madman's work was taken as an essential element. Finally, it performs a brief contextualization of the recent changings in the production process to ask how madmen can join the labor force.

Key words: work, discipline, control, psychiatrical reform.

Por ser intenção deste artigo pensar o trabalho em relação a pessoas que vivem com transtornos mentais graves, cabe, de início, apontar de que maneira a psiquiatria, desde seu surgimento, contribuiu para o ponto de vista segundo o qual aquelas pessoas são incapazes de conviver em sociedade e trabalhar. Pinel toma como fundamento, para inaugurar esse campo de saber e de intervenção médica, a concepção segundo a qual algumas pessoas eram incapazes de se guiarem por sua própria razão, alienadas, portanto. Daí a primeira denominação que a psiquiatria recebeu: "alienismo". Certamente Pinel estava inserido em seu tempo, tanto que Kant, em um texto de 1783, diz que cabe a cada ser humano buscar o esclarecimento, entendido como "(...) a saída do homem de sua menoridade, da qual ele próprio é culpado. A menoridade é a incapacidade de fazer uso de seu entendimento sem a direção de outro individuo" (Kant, 1783/1985, p. 100). Caberia, então, a cada um desenvolver a capacidade de tomar suas próprias decisões, ser senhor de seu destino, avaliar as alternativas que a vida apresenta e guiar-se por si mesmo, buscar sua emancipação. No entanto, Kant desculpa aquela menoridade, se sua causa “(...) se encontra na falta de entendimento (...)" (op. cit.). A psiquiatria surgiu exatamente por entender que os loucos eram incapazes de fazer uso da própria razão e, por isso, suas vidas deveriam ser guiadas por outrem.

\section{O Hospital Geral}

Segundo Foucault (1987, p. 48), “(...) o século XVII criou vastas casas de internamento". Essas casas não eram estabelecimentos médicos, 
mas uma estrutura semijurídica destinada a abrigar os pobres, os miseráveis, os vagabundos (op. cit., p. 63), onde os loucos ${ }^{1}$ eram trancados. O autor transcreve um fragmento do Édito Real de 1656, que criava o Hospital Geral em Paris:

"Fazemos expressa proibição a todas as pessoas de todos os sexos, lugares e idades, de toda qualidade de nascimento e seja qual for sua condição, válidos ou inválidos, doentes ou convalescentes, curáveis ou incuráveis, de mendigar na cidade e nos subúrbios de Paris, ou em suas igrejas e em suas portas, às portas das casas ou nas ruas, nem em nenhum lugar público, nem em segredo, de dia ou de noite (...) sob pena de chicoteamento para os transgressores na primeira vez, e, pela segunda vez, as galeras para os homens e meninos e banimento para as mulheres e meninas"(op. cit., p. 65).

A Europa passava por uma crise econômica, com desemprego, baixos salários, moeda escassa. Um forte conteúdo moral atribuía essa situação aos pobres com suposta tendência à vagabundagem, conforme ilustra o texto atribuído a Dekker e transcrito por Foucault: “(...) impelem seus pobres e os operários válidos que não querem trabalhar (...) a mendigar, trapacear ou roubar para viver, de modo que o país se vê miseravelmente infestado por eles" (op. cit., p. 66). Para limpar a sociedade dessa que se julgava uma infestação, estabeleceu-se o Hospital Geral. Naquele momento, o executivo e o judiciário tinham o poder de baixar ordens de reclusão (Castel, 1978, p. 29), de modo que uma pessoa poderia ser enviada para o Hospital Geral por ordem de qualquer um desses poderes, embora os atos do executivo fossem utilizados com maior freqüência por serem os processos na Justiça mais morosos e exporem mais as famílias ao olhar crítico da sociedade (op. cit.,p. 49).
No entanto, esse modelo acabou por fracassar, estando quase que totalmente extinto em toda a Europa no início do século XIX. Se, por um lado, visava abrigar os desempregados nos ateliês obrigatórios custeados pelo Estado, por outro, acabava estabelecendo uma concorrência que diminuía as vendas e aumentava o desemprego junto aos outros produtores. Além disso, o Hospital Geral tinha um custo de manutenção muito alto.

Esse mecanismo, porém, teve um papel fundamental para estabelecer uma determinada consciência ética: o valor do trabalho como eixo regulador da sociedade. Em tempos de transformação social e afirmação do poder da burguesia, a ociosidade passou a ser considerada uma afronta a Deus, e o trabalho passou a ser uma exigência irrefutável (Foucault, 1987, pp. 71-2).

Castel (1978,p. 28) mostra que, mesmo no Hospital Geral, não havia indiferenciação absoluta entre normais e loucos. No entanto, essa indiferenciação trazia conseqüências apenas administrativas, isto é, de distribuição dos internos, não gerando um olhar médico sobre a loucura.

\section{Surge o alienismo}

No contexto do Hospital Geral, o louco distinguia-se por sua resistência em subordinarse ao imperativo do trabalho como ele ali era organizado:

“(...) o momento em que a loucura é percebida no horizonte social da pobreza, da incapacidade para o trabalho, da impossibilidade de integrar-se no grupo; o momento em que começa a inserir-se no contexto dos problemas da cidade. As novas significações atribuídas à pobreza, a importância dada à obrigação do trabalho e de todos os valores éticos a ele ligados, determinam a experiência que se faz da loucura 
e modificam-lhe o sentido"(Foucault, 1987, p. 78).

Esse novo sentido atribuído a aqueles considerados incapazes de viver conforme os cânones sociais justificam o nascimento do asilo de alienados. Com a contínua ascensão da burguesia, os limites da liberdade transformam-se, de modo que não poderia mais ser suprimido sem garantias jurídicas, o que acabou por favorecer o fim dos hospitais gerais. No entanto, a subordinação da loucura ao saber médico autorizou seu confinamento em um novo espaço de reclusão: o asilo. Retomando Kant, a menoridade, vista aqui como insanidade ou alienação da razão, autoriza o nascimento do alienismo, que, posteriormente, será batizado de psiquiatria, no mesmo ato que faz surgir o asilo de alienados. A incapacidade de guiar-se nos limites estabelecidos pela moral emergente coloca o louco no lugar de quem precisa receber cuidados e proteção, ao mesmo tempo em que a sociedade também sente a necessidade de ser protegida de seus desviantes.

É interessante notar que o julgamento de incapacidade de trabalhar do louco coincide com um momento histórico em que se julgava também que os trabalhadores fossem incapazes de conduzir suas próprias vidas, de pensar por si mesmos, como mostra Castel (2001, p.305). De uma certa forma, então, pesava sobre o operário e sobre o louco um julgamento de incapacidade. No entanto, como havia a necessidade de acumulação e reprodução ampliada de capital através da produção, como salientamos, aos operários foi possível viver, e freqüentemente morrer, nessa "liberdade" que instituía a sociedade capitalista, enquanto o louco foi trancado no hospício, não podendo sequer reivindicar a entrada na produção.

Para os operários se libertarem daquele julgamento, foi necessário um longo processo, que passou também pela luta para ter sua voz ouvida e seus direitos garantidos. Encontramos ainda exemplos dessa luta no movimento dos trabalhadores, como os operários franceses, anos mais tarde, na década de 1940, reivindicando uma Medicina do trabalho que não estivesse apenas a serviço da empresa, como mostra Billiard (2001, p.55), ou ainda com os próprios operários buscando ocupar um lugar de importância na detecção e controle da nocividade no trabalho, evidenciando seu papel na construção dos conhecimentos sobre sua própria saúde no trabalho, no que ficou conhecido como Movimento Operário Italiano de Luta pela Saúde (Oddone, 1981). Essas conquistas vieram contrariar a visão de incapacidade (ou da falta de necessidade) de pensar do operário que, aliás, é um dos sustentáculos do taylorismo, onde se considerava que "(...) em quase todas as artes mecânicas, a ciência que estuda a ação dos trabalhadores é tão vasta e complicada que o operário ainda mais competente é incapaz de compreender essa ciência (...)" (Taylor, 1990, p.34).

Tomado como doente e incapaz, o louco pôde ser mantido isolado para receber o tratamento moral (Desviat, 1999, p. 17). No asilo, Pinel constituía “(...) a clínica médica como observação e análise sistemática dos fenômenos perceptivos da doença; o resultado disso foi sua nosografia" (Bercherie, 1989, p. 34). A ciência, através da Medicina, apropriouse da loucura. O alienado que não se encaixasse nas normas que a burguesia vinha estabelecendo seria isolado para receber a cura através do tratamento moral. Desviat transcreve um trecho do grande alienista Esquirol, para quem o paciente deveria ficar isolado para que se pudesse atuar “(...) diretamente sobre o cérebro e se [condenaria] $^{2}$ esse órgão ao repouso, afastando-o das impressões irritantes, reprimindo a vividez e a mobilidade das impressões e moderando a exaltação das idéias" (Esquirol apud Desviat, 1999, p. 17).
"(...) em quase todas as artes mecânicas, a ciência que estuda a ação dos trabalhadores é tão vasta e complicada que o operário ainda mais competente é incapaz de compreender essa ciência (...)"

Taylor
2 os colchetes na palavra 'condenaria' encontram-se no texto de Desviat. 
"(...) observação minuciosa do detalhe, ao mesmo tempo um enfoque político dessas pequenas coisas, para controlee utilização dos homens (...)"

Foucault
A loucura passa a ter o hospital, o asilo, como espaço de tratamento médico e isolamento.

Estabelecido como lugar de reclusão do louco, onde receberia tratamento médico, o asilo se organiza como “(...) lugar de diagnóstico e de classificação, retângulo botânico onde as espécies de doenças são divididas em compartimentos cuja disposição parece uma horta" (op. cit., p. 122). A Medicina, então, justificaria o isolamento com seu saber supostamente objetivo (Foucault, 1987, p. 498). Isso, por um lado, constituiu o nascimento das possibilidades de tratamento de que dispomos hoje, depois de uma história de continuidades e rupturas. Por outro lado, manteve confinados nos muros os loucos de quem Pinel havia anunciado a libertação.

\section{O asilo como estrutura disciplinar}

Foucault (1979) mostra que a fundação do alienismo se prestou à dominação do poder do louco, neutralizando outros poderes que poderiam recair sobre ele, submetendo-o a um poder terapêutico e de adestramento. Mostra também que essa tentativa de dominação se inscreve em um amplo movimento social de valorização da disciplina. "Os mecanismos disciplinares são, portanto, antigos, mas existiam em estado isolado até os séculos XVII e XVIII, quando o poder disciplinar foi aperfeiçoado como uma técnica de gestão dos homens" (op. cit., p. 106).

Foucault (1983) define a disciplina da seguinte forma: "Esses métodos que permitem o controle minucioso das operações do corpo, que realizam a sujeição constante de suas forças e lhes impõem uma relação de docilidade, são o que podemos chamar de "disciplinas" ( $p$. 126).

Com a disciplina, visava-se o máximo de utilização da força de um corpo dócil, enquanto capacidade de produção, e a diminuição, através da obediência, dessa mesma força enquanto poder político de transformação. Nas palavras de Foucault, tratase da "(...) observação minuciosa do detalhe, ao mesmo tempo um enfoque político dessas pequenas coisas, para controle e utilização dos homens (...)" (op. cit., p. 130). Essa anatomia do detalhe servirá para organizar os processos de produção nas fábricas, onde os operários passam a ter seu tempo, sua distribuição espacial e seus gestos absolutamente controlados, cujo auge encontramos no século $\mathrm{XX}$, com o taylorismo e o fordismo.

Note-se que estamos nos referindo a uma Europa que passava pela perda significativa de poder do soberano, conforme o Antigo Regime, e pela ascensão da burguesia. Com isso, o trabalho, a produção de riquezas e o respeito à propriedade privada adquirem valores centrais, de modo que, no bojo desse processo, se dá o incremento da disciplina. Nesse momento, a prisão passa a adquirir uma importância que não tinha até então:

"A forma geral de uma aparelhagem para tornar os indivíduos dóceis e úteis, através de um trabalho preciso sobre seu corpo, criou a instituição-prisão, antes que a lei a definisse como pena por excelência. No fim do século XVIII e princípio do século XIX, dá-se a passagem a uma penalidade da detenção, é verdade, e era coisa nova" (op. cit., p. 207).

Entretanto, no momento em que a sociedade se torna contratual, sem decisões determinadas por um soberano, e a legalidade passa a estabelecer a privação da liberdade como uma pena para os que rompem as novas regras estabelecidas, o louco coloca um problema de difícil solução. Se, por um lado, poderia ser perigoso e representar um risco à sociedade, por outro lado, perdera o que há de mais precioso no homem: a razão. Não poderia, por isso, ser responsabilizado por seus atos, do modo que a figura que se adequaria a essa situação seria a da tutela: “(...) substitutivo 
da tutelarização em relação à contratualização" (Castel, 1978, p. 44). O louco não deveria ser preso por não ser responsável por seus atos, mas, por não ser responsável por seus atos, deveria colocar-se aos cuidados e à responsabilidade de outrem:

"O indivíduo é sujeito autônomo enquanto for capaz de se dedicar a intercâmbios racionais, ou então sua capacidade de entrar num sistema de reciprocidade o isenta da responsabilidade e ele deve ser assistido. Os fundamentos contratuais do liberalismo impõem a aproximação entre o louco e a criança, a grande analogia pedagógica da Medicina mental, no seio da qual toda sua história vai desenvolver-se" (op. cit., p. 46).

Estavam prontas as condições para o chamado à Medicina, que autorizaria a reclusão do louco, no mesmo ato que justificaria sua menoridade pela nosografia nascente, estabelecendo as condições científicas para o nascimento do alienismo. O asilo torna-se, assim, uma prisão com finalidade não exatamente punitiva, mas curativa, embora a punição tenha estado presente desde o seu início. Prisão e asilo, então, no curso da História, guardam semelhanças marcantes.

\section{O hospício enquanto instituição total}

De fato, tanto as prisões quanto os hospícios enquadram-se no conceito de instituição total, conforme propõe Goffman (2001, p. 11):

"uma instituição total pode ser definida como um local de residência e trabalho, onde um grande número de indivíduos com situação semelhante, separados da sociedade mais ampla por considerável período de tempo, levam uma vida fechada e formalmente administrada."

Nas instituições totais, existe uma diferenciação bem marcada entre aqueles que são controlados, os internados, e aqueles que supervisionam as atividades, a equipe dirigente em seus diversos níveis (op. cit., p. 18). A equipe dirigente cumpre uma determinada carga horária na instituição e depois vai embora para casa, enquanto os internados não podem sair. Com isso, estes últimos têm a instituição como único local para moradia, lazer e trabalho, onde as atividades são feitas sempre em uníssono com um grupo de internos, independentemente da vontade de cada um.

Quando uma pessoa chega a uma instituição total, ela traz consigo uma concepção de si mesma que foi construída durante sua estada em seu meio doméstico. O longo período na instituição tende a fazer com que essa pessoa perca a possibilidade de manter seus papéis sociais, de modo que vai, gradativamente, perdendo a identidade que trazia consigo antes da internação (op. cit., p. 23). Desde sua chegada, esse processo vai ocorrendo através de diversas operações como, por exemplo, a retirada de todos os seus objetos pessoais. Desse modo, a essa pessoa não resta, senão, na maioria das vezes, assumir apenas uma identidade, a de interno.

Goffman mostra que os internos acabam utilizando técnicas de adaptação para tentar sobreviver a essa situação: seja através do afastamento da situação, que se segue muitas vezes a um período de intransigência e que pode levar, às vezes, a uma regressão irreversível, seja através do que o autor chama de colonização, onde o interno parece preferir a instituição ao mundo externo por este apresentar muitas situações de perigo, seja através da conversão, na qual, mais do que aceitar as posições da instituição, o internado assume uma posição moralista que defende a instituição a todo custo, seja através do que alguns internos chamam de "se virar", na qual tentam utilizar um misto de colonização, conversão e lealdade ao grupo dos internos, de modo a evitar ao máximo que sofra violência física e psicológica. $\mathrm{O}$ autor relata 
"A utilidade do trabalho penal? Não é um lucro; nem mesmo a formação de uma habilidade útil, mas a constituição de uma relação de poder, de uma forma econômica vazia, de um esquema da submissão individual e de seu ajustamento a um aparelho de produção."

Foucault ainda que, em alguns poucos casos, há situações em que, por um lado, o interno submete-se tão facilmente às pressões da instituição que se torna desnecessário o uso de técnicas específicas de adaptação e que, por outro lado, há aqueles que, por terem convicção política ou religiosa muito arraigada, conseguem manter-se relativamente imunes às pressões da instituição (op. cit., pp. 61-3) . Goffman descreve, nesse livro, diversas situações de violência em várias instituições, como em presídios, como Foucault também relata em "Vigiar e Punir" (1983), e em hospícios, como também Basaglia mostra em "As Instituições da Violência" (1985).

O trabalho dos internos nas instituições totais Na questão do trabalho dos internos, na prisão e no hospício, vamos encontrar semelhanças fundamentais, assim como em outras instituições totais.

Foucault (1983, p. 217) pontua:

"A utilidade do trabalho penal? Não é um lucro; nem mesmo a formação de uma habilidade útil, mas a constituição de uma relação de poder, de uma forma econômica vazia, de um esquema da submissão individual e de seu ajustamento a um aparelho de produção."

Goffman também apresenta vários exemplos de que o trabalho nas instituições totais se estrutura de maneira a ter o sentido de submissão. Inicialmente, ele lembra que não há, para o internado, uma cessação da autoridade do chefe, como há em situações de trabalho na vida em sociedade. Como fica o tempo todo na instituição, ele está constantemente submetido à autoridade da equipe dirigente. Além disso, geralmente as tarefas que o internado realiza são poucas, de modo que a pessoa fica entediada (Goffman, 2001, p. 21). Soma-se a isso que não há, via de regra, um pagamento formal a esse trabalho, mas, ao contrário, o pagamento se dá através de pequenos favores, como alguns cigarros, a possibilidade de usar o telefone, entre outros.

Tal vivência de trabalho no hospício pode ser grandemente nociva para os internos, pois o trabalho é elemento tão importante que até mesmo do ponto de vista da constituição da espécie foi fundamental para configurar o humano, já que podemos pensar que a evolução passou por diversas formas de trabalhar, como na confecção de ferramentas pelo homo habilis entre dois ou cinco milhões de anos atrás, ou nas organizações sociais, no neolítico, relacionadas com a produção agrícola (Schwartz,1995). Essa experiência permitiu ao humano o enfrentamento com os desafios que o meio colocava, de modo que nos permitiu chegar ao estado em que estamos hoje. Do ponto de vista de cada pessoa, consideramos que o trabalho marca cada uma a partir dos sentidos que ela estabelece para as atividades que realiza, participando de sua configuração, deixando marcas no corpo e na mente. Assim, consideramo-lo fundamental para determinar que uma pessoa se (re)estruture, de uma maneira ou de outra, que ela (re)invente a si e ao mundo ao seu redor, se (re)construa, sendo, nesse sentido, marcante para a configuração de cada humano em sua singularidade. Defendemos a idéia de que as pessoas com graves transtornos psíquicos são capazes de trabalhar, e que realizar trabalho, estarem impedidas de fazê-lo, ou ainda fazêlo segundo a lógica do hospício é algo que não lhes é indiferente, ao contrário.

Por ser de tamanha importância para cada pessoa, consideramos que o trabalho tenha grande importância na produção da saúde, mas pode também ser grandemente nocivo. Dejours (1998a, p. 164) afirma que “(..) o trabalho nunca é neutro em relação à saúde, e favorece, seja a doença, seja a saúde". Em função disso, perguntamos o que o trabalho pode trazer para pessoas reconhecidas como portadoras de transtornos mentais graves, cuidando para que isso não se torne mais uma 
tentativa de 'integração', de 'adaptação' a um sistema social patogênico. $O$ trabalho nas instituições totais - no caso que analisamos, o hospício - coloca-se como tentativa de adaptação, onde toda a diferença é submetida a uma "(...) lógica da integração (...) como se todas as outras vidas fossem vidas potencialmente doentes, que, então, é preciso reabilitá-las hoje" (Le Blanc, 2003).

Vemos, assim, que o trabalho dos internos na instituição total, incluindo aí o do louco no hospício, tem um sentido de submissão e inutilidade. Ali, então, o trabalho adquire uma capacidade de produzir doença e de ir contra o desenvolvimento pessoal do internado.

Também Schwartz (1995, p. 142) afirma que podemos “(...) caracterizar todo trabalho como lugar de uma dramática singular onde serão negociados, para cada protagonista, a articulação dos usos de si pelos 'outros' e 'por si'". Aqui, o uso de si pelos outros seria o colocar-se para que sua capacidade produtiva seja usada para realizar uma atividade, ou seja, produzir algo que se dirige a outrem. O uso de si por si diz respeito ao fato de essa pessoa utilizar seus recursos, suas capacidades, escolhendo uma determinada maneira para realizar a atividade e também os sentidos que ela dá a um trabalho e suas conseqüências. Schwartz está dizendo, então, que, no trabalho, é a pessoa por inteiro que se coloca e que ali é lugar onde cada um pode desenvolver-se, utilizando sua capacidade de produzir e de conviver, visto que as atividades de trabalho têm um aspecto de coletivo e de coordenação. Desse modo, se, no hospício, o trabalho tem o sentido de submissão e inutilidade e não tende a desenvolver a autonomia dos internos, a pessoa ali se coloca para acabar ocupando um lugar de inútil e submisso.

Percebendo o lugar central do trabalho na vida das pessoas e na estruturação do manicômio e da psiquiatria, as reformas psiquiátricas procuraram pensar o sentido e o lugar do trabalho para pessoas com transtorno mental grave, valorizando sua capacidade produtiva.

\section{As reformas psiquiátricas e as sociedades de controle}

Durante e após a 2a Guerra Mundial, ocorreram diversas tentativas de transformar ou extinguir os hospícios. Os problemas próprios da guerra haviam criado uma situação de grande penúria nos manicômios, como encontramos neste relato a propósito dos hospitais franceses:

"De um modo geral, a duração e os eventos da guerra transformaram o universo dos hospitais psiquiátricos. O racionamento de alimentos, assim como o rigor do inverno nas construções que não se podiam mais aquecer, arrastaram à morte um terço dos doentes hospitalizados. Um certo número de psiquiatras denunciaram o que eles chamaram de uma forma de 'exterminação doce'"(Billiard, 2001, p. 100).

Diante dessas dificuldades, os psiquiatras começaram a operar, durante e no pós-guerra, transformações no interior dos hospícios, em movimentos que abrangeram vários países, como a psicoterapia institucional na França, as comunidades terapêuticas na Inglaterra, a psiquiatria preventiva nos Estados Unidos e, mais tarde, a psiquiatria democrática italiana. Todos colocavam "(...) em questão a organização e, às vezes, a própria existência de instâncias oficiais responsáveis pelos doentes mentais."(Castel, 1978, p. 149).

É interessante notar que, assim como o nascimento do asilo se situou em um movimento mais amplo de práticas de confinamento, também o questionamento do hospício enquanto ideal para o tratamento da loucura se insere em um movimento mais amplo. Referimo-nos ao momento em que 
as sociedades ocidentais passaram a utilizar menos um controle disciplinar através da reclusão para utilizar mais um controle flexível que se vale de uma vigilância rarefeita e virtual: “Depois da Segunda Grande Guerra, a formafábrica, como modelo emblemático das sociedades disciplinares, começa a ser substituída por um novo modelo: a formaempresa. O confinamento e os dispositivos disciplinares que caracterizavam até então a Sociedade Moderna já dão sinais de escassez. (...) A idéia de controle a nortear uma leitura das sociedades contemporâneas (...). As sociedades disciplinares são essencialmente arquiteturais: a casa da família, o prédio da escola, o edifício do quartel, o galpão da fábrica. Por sua vez, as sociedades de controle apontam uma espécie de antiarquitetura"(Vasconcelos, 2000, p. 41).

Essa passagem não significa abolição absoluta do modelo antigo, tanto que "(...) a prisão, que é o meio de confinamento por excelência" (Deleuze, 1992), continua com grande força, com recorrentes demandas da sociedade por mais vagas nas celas. No caso do manicômio, entretanto, talvez pelo fato de o louco não ser considerado um criminoso, mas, sim, alguém que pode ser neutralizado e "docilizado" pelos saberes psi, em sociedades onde o modelo disciplinar entra em declínio, surgem, com grande força, as críticas ao manicômio. Com a perda de espaço pelo manicômio - o que não significa sua extinção, visto existir ainda hoje milhares de pessoas trancadas nele, em vários países - o louco passa a ter mais oportunidade de viver em sociedade do que havia quando o hospício não era questionado. Na verdade, tais críticas ao asilo já existiam desde, pelo menos, 1844 (Castel, 1978, p. 266), mas somente após a Segunda Guerra Mundial estas se acompanharão por práticas sólidas que o farão sentir o golpe, dando mostras de que poderá extinguir-se. Entendemos que as condições históricas construídas para isso passam exatamente para a mudança do predomínio da disciplina para o controle: não serão mais os muros que afastarão o louco, mas ele, solto na sociedade, continuará isolado. Com as novas formas de controle, poderá agora ficar "livre", mas sem grupos, sem trabalho, sem dinheiro, sem lazer e sem um elemento chave nesses novos tempos: informação.

Deleuze (1992) resume as diferenças entre os modelos da disciplina e de controle: "Os confinamentos são moldes, distintas moldagens, mas os controles são uma modulação, como uma moldagem autodeformante que mudasse continuamente, a cada instante, ou como uma peneira cujas malhas mudassem de um ponto a outro". Assim, se nas sociedades disciplinares predominam os muros para isolar os indesejáveis, nas sociedades de controle, esses indesejáveis podem, muitas vezes, ficar soltos: mas apenas se estão sob os cuidados dos saberes psi, agora nos CAPS, no caso brasileiro. Caso contrário, serão devolvidos ao manicômio ou - caso não consigam receber um diagnóstico que os coloque sob a proteção da Medicina mental - encarcerados nas prisões. No entanto, mesmo fora dos muros, continuarão isolados, pois não são capazes de se adequar à modulação, à rigidez da regra que exige, paradoxalmente, mudança permanente: constantes investimentos em formação, busca incessante de aprimoramento, utilização correta da linguagem de grupos com relativo poder social, consumo de mercadorias que oferecem status.

Não participando do grupo dos que possuem os códigos que acessam informações que permitem "trocas flutuantes" (op. cit.), isto é, trabalhar em empresas, freqüentar grupos de clubes sociais, estudar em determinadas escolas, dentre outros, e, nesses espaços, interagir conforme as regras desses lugares, o louco faz parte do grupo que não está encarcerado, mas continua isolado: "É verdade que o capitalismo manteve como constante a extrema miséria de três quartos da 
humanidade, pobres demais para a dívida, numerosos demais para o confinamento: o controle não só terá que enfrentar a dissipação das fronteiras mas também a explosão dos guetos e favelas" (op. cit.).

Entendemos, assim, que não é possível, portanto, dissociar as transformações ocorridas no seio da psiquiatria das mudanças sociais:

“(...) essas modificações (...) traduzem, ao mesmo tempo, a mudança de suas relações com outras instâncias de poder e, mais que isso, com o conjunto das práticas de controle e de normalização. Uma mudança na problemática da Medicinal mental se realiza na confluência entre essas duas séries de transformações 'internas' e 'externas'" (Castel, 1978, pp. 269-70).

Depois de mais de cem anos das propostas de Pinel de construir o asilo como lugar de isolamento e terapêutica da loucura, os psiquiatras propõem formas de tratamento que contam com o lado de fora do asilo. Alguns psiquiatras propuseram que o manicômio fosse reformado para que cumprisse função não mais de tortura e de isolamento, mas de tratamento. Os que compartilhavam desse ponto de vista consideravam necessária uma política que abrisse mais o hospital para o exterior, de modo a amenizar a cisão hospital psiquiátrico / mundo exterior. Outros propuseram que o hospício fosse sempre lugar de produção não de cura, mas de doença, reclusão e sofrimento, de modo que seria necessário acabar com ele e utilizar apenas estruturas não hospitalares (Castel, 1978, pp. 153-4). Os que compõem esse grupo sustentam que é necessário não só extinguir os hospícios como desmascarar os conceitos e as práticas psiquiátricas enquanto cumpridores de mandato social de exclusão da pessoa com transtorno mental grave, conforme as palavras de Rotelli (1990, p. 89): “(...) a instituição que colocamos em questão nos últimos vinte anos não foi o manicômio, mas a loucura".
Há, então, diferenças fundamentais entre as diversas reformas psiquiátricas. No entanto, vemos que há uma valorização, para alguns, parcial, e, para outros, absoluta, do lado de fora do hospício, isto é, da vida em sociedade. No entanto, adverte-nos Castel (1980, p.256): "O 'lado de fora' que envolve a ordem asilar pode ser também a ordem social e os mecanismos de uma sociedade liberal que deu origem à instituição totalitária como uma resposta aos problemas postos por um novo modo de integração dos indivíduos a novas normas de produtividade e de controle social."

Seguindo Castel, podemos perguntar se, com o declínio ou extinção do hospício, a pessoa com transtorno mental grave continuará isolada, mesmo que vivendo em sociedade, ou seja, vivendo do lado de fora do hospício. Conforme expusemos, reconhecemos que esse processo de reforma psiquiátrica que tem ocorrido nas últimas décadas se insere em um processo de transformação social mais amplo, nos quais os dispositivos institucionais se tornaram mais sutis, menos evidentes, de modo mais sofisticado que nos modelos disciplinares, com as novas tecnologias sendo utilizadas para a realização do controle. Desse modo, sabemos que as transformações da assistência, da visão social e da luta dos direitos da pessoa com transtorno mental grave, são fruto de um processo ocorrido dentro e fora da psiquiatria. No entanto, reconhecemos que essas transformações são favoráveis à pessoa com transtorno mental grave, isto é, que o declínio do hospício torna as pessoas menos sujeitas a serem trancadas e a sofrerem as violências que, freqüentemente, ocorrem dentro do manicômio e que, além disto, abrem-se possibilidades para elas poderem orientar suas próprias vidas, tornando-se cada vez mais autônomas. Nesse sentido, podemos procurar saber de que maneira pode ser possível a essas pessoas, não mais internadas no manicômio, viverem nessa sociedade segregatória sem serem isoladas. Pensamos que isso pode ser possível através de sua inserção no mundo do trabalho. 


\section{Mudanças nos sistemas produtivos: há lugar para quem?}

Sabemos que, nas últimas décadas, ocorreram grandes mudanças nos sistemas produtivos que levaram a uma automatização e substituição do trabalho humano por máquinas robotizadas devido ao fato de as empresas buscarem maior competitividade. Além disso, o Estado, em muitos países do Ocidente, deixou de ter a função de garantir proteção a seus cidadãos, trazendo um período de perda de muitos direitos. No Brasil, onde o Estado nunca exerceu verdadeiramente a função de proteger seus cidadãos, isso pode ser observado pela perda de direitos previdenciários, crescimento nos índices de desemprego, privatização crescente de educação e saúde, entre outras coisas. Esses fenômenos, somados, levaram a uma crise das condições de trabalho e de empregabilidade, como nos indica Castel (1998, p.514): "Mas o desemprego é apenas a manifestação mais visível de uma transformação profunda da conjuntura do emprego. A precarização de trabalho constituiIhe uma outra característica, menos espetacular, porém ainda mais importante, sem dúvida."

Acrescentamos a afirmação de Antunes (2000, pp. 159-160):

"Em verdade, o sistema de metabolismo social do capital necessita cada vez menos do trabalho estável e cada vez mais das diversificadas formas de trabalho parcial ou part-time, terceirizado (...), que se encontram em explosiva expansão em todo o mundo produtivo e de serviços."

Observamos, com isso, que, mesmo para o trabalhador que não apresenta previamente nenhuma alteração mental importante, as condições parecem estar cada vez menos favoráveis. Pensamos que o trabalho não deixou de ser central na vida das pessoas, mas que o mercado está cada vez mais desfavorável ao humano. O problema, então, não é do trabalho, mas do mercado, das regras do jogo do capital. No entanto, sabemos que precisamos pensar o trabalho considerando o mercado, já que estamos lidando com sujeitos humanos nessa conjuntura. Como podemos, nesse contexto, pensar em trabalho para pessoas que estão em desvantagem desde antes da entrada na colocação no trabalho, como as pessoas com transtorno mental grave? Pensamos ser essa uma questão que devemos enfrentar, isto é, se as condições estão difíceis e desfavoráveis, é exatamente nesse momento que se tornam urgentes soluções para tais questões.

Conforme apontamos anteriormente, as diversas iniciativas de reformas psiquiátricas têm procurado possibilitar a oportunidade de trabalho para aqueles que historicamente foram trancados no hospício. De fato, encontramos nas experiências das comunidades terapêuticas e da psicoterapia institucional, influenciadas pela ergoterapia, de Hermann Simon, o trabalho como elemento importante nas organizações de estruturas de tratamento em psiquiatria (Desviat, 1999, pp. 30-4). Posteriormente, a experiência de reforma na Itália trouxe a valorização das cooperativas de trabalho dos pacientes, levando ao surgimento das empresas sociais (Rotelli, 2000, pp. 301-6).

No Brasil, várias experiências têm se realizado no sentido de criar condições de trabalho nesse sentido. Em recente tese de doutoramento, Telles (2002), em uma pesquisa desenvolvida a partir de uma experiência de trabalho na Cooperativa da Praia Vermelha, onde trabalham pessoas que se tratam em serviços públicos de saúde mental no Município do Rio de Janeiro, mostra como, em situações de trabalho, essas pessoas conseguem desenvolver-se e como ali elas encontram condições de levar uma vida melhor. Os relatos dos membros desse tipo de cooperativa mostram que, para eles, apesar de 
reconhecerem, por vezes, alguma dificuldade no aprendizado do processo de produção, e de ter que lidar com dificuldades próprias de seu funcionamento devido ao seu processo de adoecimento e de seus companheiros (pp. 84-85), o trabalho na Cooperativa traz, inicialmente, o benefício de levar a uma ocupação fora de casa, já que ficar em casa freqüentemente traz aumento de tensão com familiares e vizinhos (p. 81).

De 1992 até o início de 2002, o autor deste artigo trabalhou em unidades de tratamento em saúde mental, tanto em hospital geral quanto em ambulatório ou ainda em centro de atenção psicossocial, exercendo a função de psicólogo ou de coordenador de unidade. Nesse período, os usuários verbalizaram por diversas vezes a vontade de exercer atividades de trabalho, mostrando-se insatisfeitos de ficar sem trabalhar, queixando-se de ficar em casa, dizendo sentir-se entediados. Uma vez tendo conseguido realizar esse desejo e colocar-se em situação de trabalho, que possibilidades se abrem para suas vidas a partir disso?

Em Volta Redonda, cidade situada ao sul do Estado do Rio de Janeiro, em função do desejo expresso pelos usuários de trabalhar, realizamos uma experiência de produção e venda de artesanatos em um centro de atenção psicossocial que coordenamos até março de 2002. Batizada pelos usuários de "Bazarte", a idéia era que pessoas que estavam com pouca oportunidade de trabalho que não fosse o trabalho doméstico pudessem exercer atividade de trabalho remunerada. Surgiram dificuldades ligadas à estruturação da produção, no que diz respeito, sobretudo, à inconstância no fornecimento de matéria prima, já que a venda dos materiais era insuficiente para manter o abastecimento, sendo necessário o envio dos materiais pela Secretaria Municipal de Saúde, tendo, assim, que atender à Lei n.8666, que regula as compras pelo serviço público e torna lentos os processos de compra. Além disso, não foi possível conseguir um local adequado para produção e venda, de modo que tudo acontecia no próprio CAPS, o que acabava, por vezes, não contribuindo para o crescimento do Bazarte. De fato, Leonardis, Mauri \& Rotelli (1994) pontuam que as iniciativas de trabalho para pessoas com transtorno mental grave devem acontecer preferencialmente fora do espaço reservado para assistência. Havia ainda questões ligadas ao INSS, já que as pessoas que tinham benefícios da Previdência ou eram aposentadas tinham receio de trabalhar devido ao risco de serem descobertos pela fiscalização previdenciária e perderem seus direitos.

Essas pessoas mostram também que, em casa, seu trabalho freqüentemente não é reconhecido e que, nas cooperativas, elas encontram esse reconhecimento. Sabemos hoje, a partir das proposições de autores como Dejours (1998b), que o reconhecimento e a valorização social do trabalho é elemento fundamental para a produção de prazer e saúde para qualquer pessoa. Nas cooperativas, existe também a possibilidade de ganhar dinheiro, abrindo a perspectiva de poder, um dia, prescindir do chamado benefício do INSS que, para a pessoa poder receber, tem que estar alimentando constantemente uma incapacidade.

O texto de Telles traz o relato dos membros da Cooperativa, mostrando que o trabalho ali aumenta sua capacidade de compreender melhor a si mesmo a aos outros, desenvolvendo significativamente sua habilidade de comunicação (op. cit., p. 85), o que vai de encontro à afirmação de Zarifian (2001, pp. 45-48), que mostra que as transformações recentes nos sistemas produtivos exigem, cada vez mais, a capacidade do trabalhador de comunicar-se e de entender as necessidades dos outros trabalhadores e dos clientes.

Telles mostra também que o trabalho naquela cooperativa permite aos seus membros ter a 
perspectiva de voltar a trabalhar em sua profissão, que, muitas vezes, é abandonada por ocasião de uma crise. Experiências simples como a Cooperativa da Praia Vermelha ou o Bazarte mostram como essas pessoas têm a capacidade de desenvolver suas competências, apesar do processo de adoecimento.

No entanto, há que se observar que essas iniciativas são ainda incipientes e pouquíssimo lucrativas.

\section{Conclusão}

Como dissemos, a queda da hegemonia do modelo disciplinar, somada aos problemas enfrentados nos hospícios, deu margem ao surgimento de uma série de transformações na psiquiatria, as chamadas reformas psiquiátricas. Cabe, ainda, operar transformações que possam garantir que a pessoa com transtorno mental grave possa viver bem em sociedade, desfrutando de seus prazeres. Para isso, sabemos que é fundamental que as pessoas tenham dinheiro e trabalho, sem precisar ficar dependendo das misérias da previdência social. No entanto, essa parece ser uma conquista ainda distante.

Será possível que, nesta sociedade discriminatória, essas pessoas poderão encontrar espaços fora do trabalho protegido para que possam produzir e desenvolver-se? Já não sabemos que muitas dessas pessoas, anonimamente e fora dos serviços de saúde, estão conseguindo fazer isso de maneira discreta? O desafio está colocado. Cabe-nos enfrentá-lo. 
Paulo César Zambroni de Souza

Psicólogo.Professor Adjunto da Universidade Federal de Itajubá - UNIFEI Doutor em Psicologia Social pela Universidade do Estado do Rio de Janeiro, sob a orientação de Milton Athayde. Mestre em Psicologia pela Universidade Federal do Rio de Janeiro.

AV. BPS, no 1303, Bo Pinheirinho, Itajubá - MG, CEP 37500-903

Tel: (35) 36291150

E-mail:paulozamsouza@yahoo.com.br

Recebido 05/01/04 Reformulado 16/02/06 Aprovado 14/03/06

ANTUNES, Ricardo. Adeus ao Trabalho? Ensaio sobre as Metamorfoses e a Centralidade do Mundo do Trabalho. 7 a ed. São Paulo: Cortez; Campinas: Editora da Universidade Estadual de Campinas, 2000.

BASAGLIA, Franco. As Instituições da Violência. In Basaglia, et al. A Instituição Negada: Relato de um Hospital Psiquiátrico. Rio de Janeiro: Graal, 1985.

BERCHERIE, Paul. Os Fundamentos da Clínica: História e Estrutura do Saber Psiquiátrico. Rio de Janeiro: Jorge Zahar, 1989.

BILLIARD, Isabelle. Santé Mentale et Travail: I' Émergence de la Psychopathologie du Travail. Paris: La Disputel/Snédit, 2001.

CASTEL, Robert. A Ordem Psiquiátrica: a Idade de Ouro do Alienismo. Rio de Janeiro: Graal, 1978.

A Instituição Psiquiátrica em Questão. In Figueira

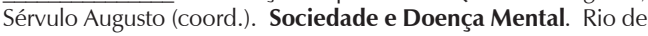
Janeiro: Campus, 1978.

Rumo às Novas Fronteiras da Medicina Mental. In Figueira, Sérvulo Augusto. Psicanálise e Ciências Sociais. Rio de Janeiro: Francisco Alves, 1980

As Metamorfoses da Questão Social: uma Crônica do Salário. Petrópolis: Vozes, 1998.

DEJOURS, Cristophe. A Loucura do Trabalho: um Estudo de Psicopalogia do Trabalho. 5ae ed. São Paulo: Cortez-Oboré, 1998a.

Souffrance en France. La Banalisation de I'Injustice Sociale. Paris: Le Seuil, 1998b.

DELEUZE, Gilles. Post Scriptum sobre a Sociedade de Controle. 1992. Disponível em: http://geocities.yahoo.com.br/guaikuru0003/ deleuze_pos_scriptum.html. Acessado em 15/01/2005.

DESVIAT, Manuel. A Reforma Psiquiátrica. Rio de Janeiro: Fiocruz, 1999.

FOUCAULT, Michel. Microfísica do Poder. Rio de Janeiro: Graal, 1979.

. Vigiar e Punir. Petrópolis: Vozes, 1983.

Paulo: Perspectiva, 1987.
GOFFMAN, Erving. Manicômios, Prisões e Conventos. 7ª ed. São Paulo: Perspectiva, 2001.

KANT, Immanuel. Resposta à Pergunta: que é "Esclarecimento"? In Textos Seletos. Petrópolis: Vozes, 1985.

LE BLANC, Guillaume. Les Maladies de l'Homme Normal. Passant $\mathbf{n}^{\circ}$ 45-46 [juin2003 - septembre 2003]. Disponível em: http:// www.passantordinaire.com/revue/prin.qsp ?id $=558$. Acessado em $10 / 10 / 2004$

LEONARDIS, Otta; MAURI, Diana; ROTELLI, Franco. La Empresa Social. Buenos Aires: Nueva Visión, 1994.

ODDONE, Ivar. Redécouvrir l'Expérience Ouvrière. Paris: Sociales, 1981.

ROTELLI, Franco. Empresa Social: Construindo Sujeitos e Direitos. In Amarante, P. D. C. (org.). Ensaios: Subjetividade, Saúde Mental, Sociedade. Fio de Janeiro: Fiocruz, 2000.

. A Instituição Inventada. In Rotelli, F.; Leonardis, O. de Mauri, D.; Risio, C. de. Desinstitucionalização. São Paulo: Hucitec, 1990

SCHWARTZ, Yves. Circulations, Dramatiques, Efficacités de l' Activité Industrieuse. In Bidet, J., Texier, J. (orgs). La Crise du Travail. Paris: PUF, 1995.

TAYLOR, Frederick. Princípios de Administração Científica. 8ae ed. São Paulo: Atlas, 1990

TELLES, Ana Luíza Corrêa. Trabalhando como Loucos: em Busca de Novas Formas de Organização do Trabalho a Partir de um Estudo da Cooperativa da Praia Vermelha. 129 f. Tese de Doutorado em Engenharia de Produção. Coordenação de Pós-graduação e Pesquisa em Engenharia/Universidade Federal do Rio de Janeiro, Rio de Janeiro, 2002.

VASCONCELOS, Jorge. A Cidade Sob Controle: Subjetividades e Tecnologia do Virtual. Revista Logos. Faculdade de Comunicação, UERJ, Ano 7, n ${ }^{\circ} 12,1^{\circ}$ Semestre, 2000.

ZARIFIAN, Philippe. Objetivo Competência: por uma Nova Lógica. São Paulo: Atlas, 2001.
Referências 